\title{
Children with cervical lymphadenopathy: reactive or not?
}

\author{
Hilal Susam Şen ${ }^{1 \oplus}$, Süheyla Ocak ${ }^{1 \oplus}$, Pınar Yılmazbaş \\ ${ }^{1}$ Division of Pediatric Oncology, ${ }^{2}$ Department of Pediatrics, Health Sciences University, Okmeydan Training and Research Hospital, \\ Istanbul, Turkey.
}

\begin{abstract}
Background. This study aims to evaluate the etiology of cervical lymphadenopathies in children and to define the significance of demographic, clinical, and laboratory features in the prediction of malignancy.

Methods. Medical records of 527 patients were reviewed retrospectively between 2015 and 2019. The patients were examined in terms of demographics, clinical, radiologic, and serologic findings. A lymph node biopsy was performed in selected patients. The risk factors for malignancy were evaluated.

Results. Out of 527 children, 26 had neck masses mimicking lymphadenopathy; 501 had lymphadenopathy. The most common location was the anterior cervical region and the median age was 5.7 years. Thirty-nine patients had malignancy (lymphoma in 34, nasopharyngeal carcinoma in 3, leukemia in 1 and neuroblastoma in 1). The risk of malignancy was associated with older age, duration of $>4$ weeks, lymph node size $>3 \mathrm{~cm}$, supraclavicular location, presence of systemic symptoms, and hepatosplenomegaly ( $<<0.001, p<0.001, p<0.001, p<0.001, p<0.001$, $\mathrm{p}<0.001$ ). On laboratory evaluation, anemia, leukocytosis, and increased erythrocyte sedimentation rate were found to be associated with malignancy $(\mathrm{p}<0.001, \mathrm{p}=0.003, \mathrm{p}<0.001)$.
\end{abstract}

Conclusions. Cervical lymphadenopathies in children are generally benign but patients with persisting cervical lymphadenopathy, adolescent age, accompanying systemic symptoms and abnormal laboratory findings should be considered for an early biopsy.

Key words: cervical lymphadenopathy, children, malignancy, reactive lymphoid hyperplasia, supraclavicular location.

Neck masses in children have a wide range of differential diagnosis including congenital anomalies, infectious or inflammatory diseases, and malignant lesions. ${ }^{1}$ Cervical lymphadenopathy (LAP) is the most common cause of a neck mass in childhood with estimates of 38 to $45 \%$ of otherwise healthy children. ${ }^{2} \mathrm{Up}$ to $90 \%$ of children between the ages of $4-8$ years have palpable cervical lymph nodes due to a physiologic increase in lymphoid tissue by age. ${ }^{3}$ Acute upper respiratory tract infections and infectious lymphadenitis are the major causes of enlarged cervical lymph nodes which usually regress spontaneously or with medication. Also, reactive hyperplasia of lymphatic tissue

\section{Hilal Susam Şen}

hilalsusam@hotmail.com

Received 10th June 2020, revised 29th July 2020,

15th September 2020, accepted 28th September 2020. mainly due to local inflammation is very common in children. However, in clinical practice accurate and prompt diagnosis of malignancy is of importance, even if it is relatively rare. The primary goal in dealing with cervical masses in children is to define the essential workup and intervention algorithms for the diagnosis of malignant lesions while avoiding unnecessary diagnostic tests and therapies. ${ }^{4}$ Several studies have shown that progressive increase in size, unresponsiveness to therapy, presence of systemic signs and symptoms, and abnormal leukocyte counts and high erythrocyte sedimentation rate (ESR) may indicate malignancy. ${ }^{2}$ Aside from the malignancy, the presence of endemic diseases or regional factors affect the distribution of nonmalignant diagnosis admits with cervical LAP. In this study, we evaluated 527 children with cervical mass to determine common etiologies 
for cervical LAP in children and to define any clinical, laboratory, and pathological findings alarming for malignancy.

\section{Material and Methods}

In this retrospective single center study 527 consecutive patients under the age of 19 years admitted to the Pediatric Oncology Department from 2015 to 2019 were evaluated. From each record we collected information regarding age, gender, medical history (including dental problems), sore throat, fever, cough, history of upper respiratory tract infection, animal contact and travel, duration of symptoms, and clinical course. Physical examination was noted for the location, size, laterality, mobility, and tenderness of the lymph node; associated systemic symptoms including weight loss, night sweats, fever, and hepatosplenomegaly for each patient. The patients were categorized into age categories ( $0-23$ months, $\geq 24$ months to $<12$ years, and $\geq 12$ to 19 years). Complete blood count, ESR, lactate dehydrogenase (LDH), and C-reactive protein (CRP) levels were noted. Additional studies (the tuberculin skin test, serological tests for Epstein-Barr virus (EBV), cytomegalovirus, rubella, toxoplasmosis, Brucella, Mycobacterium tuberculosis, and human immunodeficiency virus, bone marrow examination, two-dimensional chest $\mathrm{X}$-ray and ultrasonography) were also performed based on the clinical features. An excisional biopsy was performed in the case of suspected malignancy.

The lymph nodes were classified according to the anatomical region, size $(<1 \mathrm{~cm}, 1-3 \mathrm{~cm}$, $>3 \mathrm{~cm}$ ), extension (unilateral and bilateral), the number of involved sites (localized / one anatomic region or generalized / 2 or more noncontiguous lymph node regions) and the duration (less than 2 weeks, 2-4 weeks and $>4$ weeks). Lymph node size, extension, and the number of involved sites were evaluated by physical examination.

The clinical and laboratory features of malignant and benign cases were evaluated separately.
Also, the cases with the benign diagnosis were grouped in eight as follows: reactive lymphoid hyperplasia, reactive micro-lymphadenopathy $(<1 \mathrm{~cm})$, EBV infection, infectious lymphadenitis, cat-scratch disease, abscess, tuberculosis lymphadenitis, and others (such as Castleman disease). Reactive lymphoid hyperplasia was described as a normally shaped and structured, but enlarged lymph node with a history of the previous infection and the absence of clinical signs of inflammatory disease. Children with complaints of snoring, sleeping difficulty, breathing through the mouth, hypo nasal speech, and recurring respiratory infections were noted for adenoid vegetation.

The data were analyzed using the statistical package for social sciences (SPSS, version 18). Comparisons of groups were made by using Chi-square or Fisher's exact test. A p-value of less than 0.05 was considered significant.

This study was approved by the Noninterventional Clinical Research Ethics Board of Health Science University Okmeydani Training and Research Hospital (2019/1304). All parents gave written informed consent for the study. It was performed in compliance with the 2009 Declaration of Helsinki.

\section{Results}

Between 2015 and 2019, a total of 527 patients referred to our hospital with complaints of neck masses. Out of 527 patients, 26 who had neck masses mimicking LAP are listed in Table I. Their ages ranged from 1 month to 16.2 years with a median of 5.7 years. Most patients were male (male/female:16/8).

Of the 527 patients, 501 had cervical lymphadenopathy. Of these, 333 (66.5\%) were males and $168(33.5 \%)$ were females with a median age of $7.3 \pm 4.2$ years (0.4-18 years). The diagnosis of cases with cervical LAP is listed in Table II. The median ages of patients with benign and malignant LAP were 6.8 years (range 4.8 months-18 years) and 12.7 years (range, 2.1-17.1 years) respectively. 
Table I. Neck masses mimicking lymphadenopathy.

\begin{tabular}{lc}
\hline Diagnosis & Number \\
\hline Torticollis & 4 \\
Thyroglossal duct & 4 \\
Lymphangioma & 4 \\
Branchial cleft cyst & 3 \\
Neurofibroma & 2 \\
Pilomatrixoma & 2 \\
Ectopic thymus & 1 \\
Hemangioma & 1 \\
Vascular malformation & 1 \\
Fibromatosis & 1 \\
Nodular fasciitis & 1 \\
Benign lymphoepithelial cyst & 1 \\
Spindle cell mesenchymal tumor & 1 \\
\hline
\end{tabular}

Table II. Diagnosis of cases with cervical lymphadenopathy.

\begin{tabular}{|c|c|c|}
\hline Diagnosis & Number & $\%$ \\
\hline Malignant & 39 & 100 \\
\hline Hodgkin lymphoma & 29 & 74.3 \\
\hline Non-Hodgkin lymphoma & 5 & 12.8 \\
\hline Nasopharyngeal carcinoma & 3 & 7.6 \\
\hline Leukemia & 1 & 2.5 \\
\hline Neuroblastoma & 1 & 2.5 \\
\hline Benign & 462 & 100 \\
\hline $\begin{array}{l}\text { Reactive lymphoid } \\
\text { hyperplasia }\end{array}$ & 321 & 69.4 \\
\hline Unknown & 199 & 43 \\
\hline $\begin{array}{l}\text { Viral upper respiratory } \\
\text { infection }\end{array}$ & 67 & 14.5 \\
\hline Adenoid vegetation & 23 & 4.9 \\
\hline Tooth decay & 9 & 1.9 \\
\hline Tonsillitis & 9 & 1.9 \\
\hline Dermatitis on scalp & 5 & 1 \\
\hline Other & 9 & 1.9 \\
\hline $\begin{array}{l}\text { Reactive micro- } \\
\text { lymphadenopathy }\end{array}$ & 78 & 16.8 \\
\hline Ebstein-Barr virus infection & 32 & 6.9 \\
\hline Lymphadenitis & 11 & 2.3 \\
\hline Cat scratch disease & 7 & 1.5 \\
\hline Abscess & 5 & 1 \\
\hline Tuberculosis lymphadenitis & 4 & 0.8 \\
\hline Castleman disease & 2 & 0.4 \\
\hline $\begin{array}{l}\text { Chronic granulomatosis } \\
\text { disease }\end{array}$ & 1 & 0.2 \\
\hline Rosai-Dorfman disease & 1 & 0.2 \\
\hline
\end{tabular}

Cervical LAP was unilateral in 120 children $(23 \%)$ and bilateral in $381(76 \%)$ cases. The most common etiology was reactive lymphoid hyperplasia (69\%). A specific etiology such as Ebstein-Barr virus infection, acute infectious lymphadenitis, cat-scratch disease, abscess, and tuberculosis lymphadenitis was found in only $12 \%$ of patients in children with a benign diagnosis. Hodgkin lymphoma was the most common cause of the malignant LAP group (74\%). Empirical antibiotic therapy was started for all infectious lymphadenitis and most of the reactive lymphoid hyperplasia with the LAP size larger than one $\mathrm{cm}$. Lymph node biopsy was performed in $62(12 \%)$ cases because of one of the following factors: fixed and hard lymph nodes, supraclavicular localization, progressive increase in size, unresponsiveness to empirical antibiotics, the presence of constitutional symptoms like a fever of unknown origin, night sweats or weight loss. Thirty-eight $(61.3 \%)$ of 62 biopsies were reported to be malignant. All patients who had undergone biopsy were over the age of two years. Histopathological diagnosis according to the age groups is shown in Table III.

The most common localizations were upper anterior cervical $(43 \%)$ and submandibular region $(27 \%)$. The local features, clinical characteristics, and laboratory results of benign and malignant LAP groups are compared in Table IV. Patients between the ages of 12 and 19 years were mainly presented with chronic and

Table III. Histopathological diagnoses of the biopsies according to age groups.

\begin{tabular}{|c|c|c|}
\hline \multirow{2}{*}{ Diagnosis } & \multicolumn{2}{|c|}{$2-12$ years $12-18$ years } \\
\hline & $(\mathrm{n}=30)$ & $(n=32)$ \\
\hline $\begin{array}{l}\text { Reactive lymphoid } \\
\text { hyperplasia }\end{array}$ & 11 & 4 \\
\hline Hodgkin lymphoma & 8 & 21 \\
\hline Non-Hodgkin lymphoma & 3 & 2 \\
\hline Nasopharyngeal carcinoma & 2 & 1 \\
\hline Neuroblastoma & 1 & 0 \\
\hline Other* & 5 & 4 \\
\hline
\end{tabular}


Table IV. Clinical characteristics and laboratory results of lymphadenopathy in the benign and malignant groups.

\begin{tabular}{|c|c|c|c|c|}
\hline & & & & \\
\hline & $\mathrm{n}$ & $\%$ & $\mathrm{n}$ & $\%$ \\
\hline Age group & & & & \\
\hline $0-2$ years & 43 & (9.3) & 0 & 0 \\
\hline 2-12 years & 363 & (78.7) & 15 & (38.5) \\
\hline $12-18$ years & 55 & (11.9) & 24 & (61.5) \\
\hline & & & & \\
\hline Location & & & & \\
\hline Supraclavicular & 1 & $(0.2)$ & 22 & $(56.4)$ \\
\hline Other & 460 & (99.8) & 17 & $(43.6)$ \\
\hline & & & & \\
\hline Extension & & & & \\
\hline Local & 439 & (95) & 34 & (87) \\
\hline Generalized & 22 & (5) & 5 & (13) \\
\hline & & & & \\
\hline Size & & & & \\
\hline$<1 \mathrm{~cm}$ & 101 & (21.9) & 0 & 0 \\
\hline $1-3 \mathrm{~cm}$ & 327 & $(70.9)$ & 7 & $(17.9)$ \\
\hline$>3 \mathrm{~cm}$ & 33 & $(7.2)$ & 32 & $(82.1)$ \\
\hline & & & & \\
\hline Duration & & & & \\
\hline$<2$ weeks & 36 & (7.8) & 1 & (2.6) \\
\hline 2-4 weeks & 274 & (59.4) & 8 & (20.5) \\
\hline$>4$ weeks & 151 & $(32.8)$ & 30 & $(76.9)$ \\
\hline & & & & \\
\hline Laterality & & & & \\
\hline Bilateral & 366 & (79.4) & 15 & (38.5) \\
\hline Unilateral & 95 & (20.6) & 24 & (61.5) \\
\hline & & & & \\
\hline Hepatosplenomega & & & & \\
\hline Positive & 13 & (2.8) & 7 & (17.9) \\
\hline Negative & 448 & (97.2) & 32 & (82.1) \\
\hline & & & & \\
\hline Associated symptor & & & & \\
\hline Positive & 36 & (7.8) & 15 & (38.5) \\
\hline Negative & 425 & $(92.2)$ & 24 & (61.5) \\
\hline & & & & \\
\hline Pathological LAP $x x$ & & & & \\
\hline Yes & 63 & (13.7) & 39 & (100) \\
\hline No & 398 & (86.3) & 0 & 0 \\
\hline & & & & \\
\hline
\end{tabular}

x: Fisher's Exact test; ${ }^{\mathrm{xx}}$ : fever, night sweats, weight loss; ${ }^{\mathrm{xxx}}$ : hard, fixed, conglomerate 
Table IV. Continued.

\begin{tabular}{|c|c|c|c|c|}
\hline & \multicolumn{2}{|c|}{$\begin{array}{l}\text { Benign LAP } \\
\qquad(\mathrm{n}=461)\end{array}$} & \multicolumn{2}{|c|}{$\begin{array}{l}\text { Malignant LAP } \\
\quad(n=39)\end{array}$} \\
\hline & $\mathrm{n}$ & $\%$ & $\mathrm{n}$ & $\%$ \\
\hline \multicolumn{5}{|l|}{ Course of LAP } \\
\hline Same size/increase in size & 123 & $(26.7)$ & 39 & (100) \\
\hline \multirow[t]{2}{*}{ Decrease in size } & 338 & $(73.3)$ & 0 & 0 \\
\hline & \multicolumn{4}{|c|}{$p<0.001$} \\
\hline Anemia & $(\mathrm{n}=450)$ & & & \\
\hline Yes & 72 & (16) & 23 & (59) \\
\hline \multirow[t]{2}{*}{ No } & 378 & (84) & 16 & (41) \\
\hline & \multicolumn{4}{|c|}{$p<0.001$} \\
\hline Leukocytosis & $(\mathrm{n}=450)$ & & & \\
\hline Yes & 109 & $(24.2)$ & 18 & $(46.2)$ \\
\hline \multirow[t]{2}{*}{ No } & 341 & $(75.8)$ & 21 & $(53.8)$ \\
\hline & \multicolumn{4}{|c|}{$p=0.003$} \\
\hline Platelet count & $(\mathrm{n}=450)$ & & & \\
\hline Elevated & 30 & (7) & 12 & (30) \\
\hline \multirow[t]{2}{*}{ Normal/low } & 420 & (93) & 27 & (70) \\
\hline & \multicolumn{4}{|c|}{$p<0.001$} \\
\hline Erythrocyte sedimentation rate & $(\mathrm{n}=247)$ & & $(\mathrm{n}=36)$ & \\
\hline Normal & 207 & $(83.8)$ & 15 & $(41.7)$ \\
\hline \multirow[t]{2}{*}{ Elevated } & 40 & $(16.2)$ & 21 & $(58.3)$ \\
\hline & \multicolumn{4}{|c|}{$p<0.001$} \\
\hline Lactate dehydrogenase & $(n=252)$ & & $(\mathrm{n}=38)$ & \\
\hline Normal & 241 & (95.6) & 36 & $(94.7)$ \\
\hline \multirow[t]{2}{*}{ Elevated } & 11 & $(4.4)$ & 2 & (5.3) \\
\hline & \multicolumn{4}{|c|}{$p=0.682$} \\
\hline $\mathrm{C}$ - reactive protein & $(n=198)$ & & $(\mathrm{n}=32)$ & \\
\hline Normal & 140 & (70.7) & 19 & $(59.4)$ \\
\hline \multirow[t]{2}{*}{ Elevated } & 58 & (29.3) & 13 & $(40.6)$ \\
\hline & \multicolumn{4}{|c|}{$p=0.198$} \\
\hline
\end{tabular}

${ }^{\mathrm{x}}$ : Fisher's Exact test; ${ }^{\mathrm{xx}}$ : fever, night sweats, weight loss; ${ }^{\mathrm{xxx}}$ : hard, fixed, conglomerate

localized LAP and a biopsy was performed in $40 \%$ of the age group. Clinical characteristics of LAP according to the age groups are shown in Table V.

\section{Discussion}

Cervical LAP in children is one of the most common reasons for admission to pediatric departments. ${ }^{1-3}$ As seen in our series, neck masses including congenital cystic lesions, vascular malformations, and benign tumors may also mimic LAP and be referred to a pediatrician or a pediatric oncologist. ${ }^{3,5}$

The various diseases may cause cervical LAP; the most common etiology in children is reactive lymphoid hyperplasia following a viral or bacterial infection that resolves without any sequela within a limited period. ${ }^{2,6}$ In our study, 
Table V. Clinical characteristics of lymphadenopathy according to the age groups.

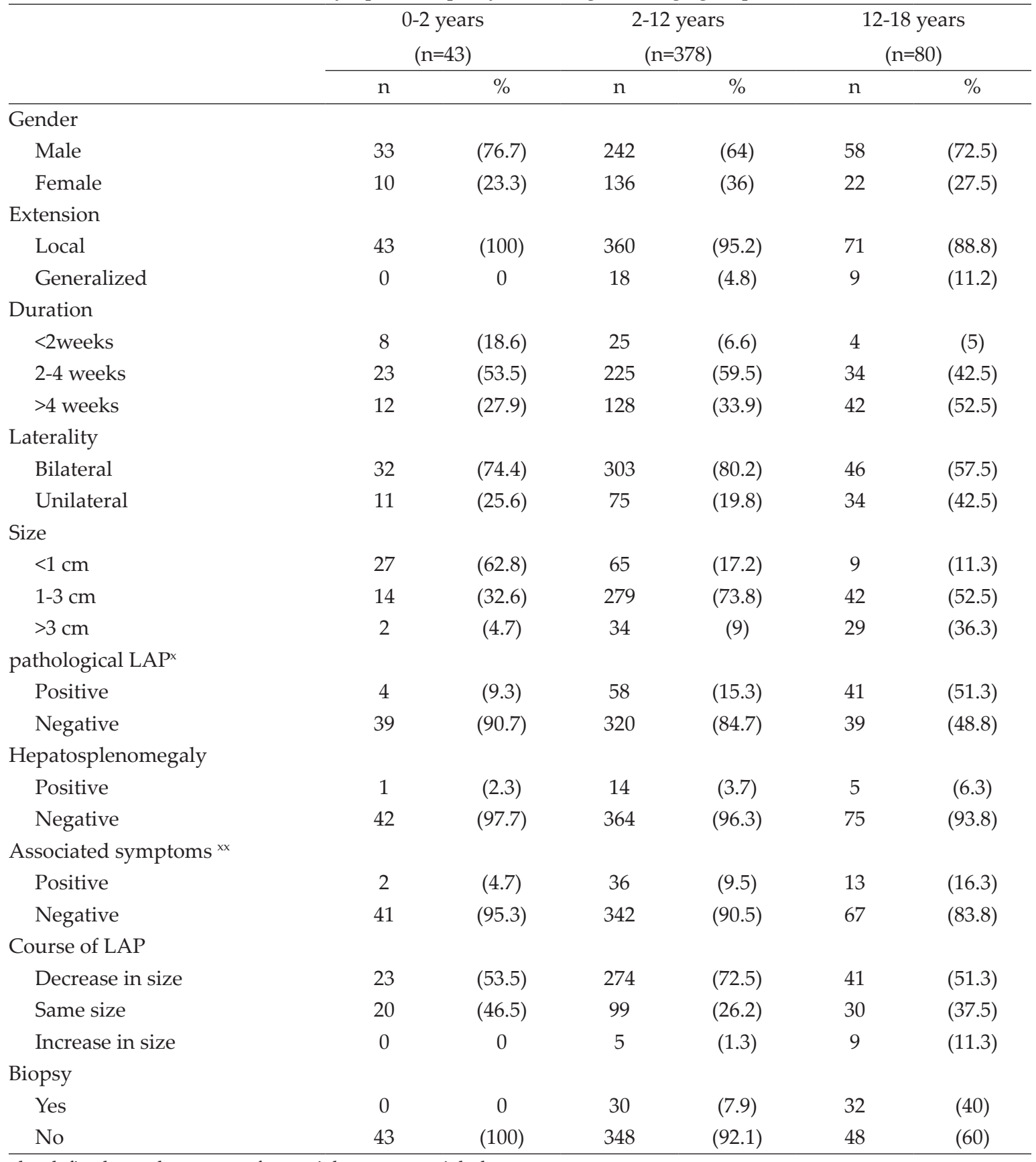

x:hard, fixed, conglomerate; ${ }^{\mathrm{x} x}$ :fever, night sweats, weight loss

nearly $80 \%$ of patients had reactive lymphoid hyperplasia and this percentage is higher than the percentage in other studies., ${ }^{2,3}$ The reason for this high percentage can be explained by the inclusion of LAP smaller than one $\mathrm{cm}$ in our study.
In cervical LAP, clinical history, physical examination, and laboratory findings provide valuable signs for the diagnosis of the majority of cases. ${ }^{5}$ However, excisional biopsy is required in some cases for the definitive diagnosis. The rate of reported incidences of 
malignancy in pediatric cervical LAPs varies from $1 \%$ to $72 \% .^{6-11}$ In our study, the pathologic examination was required in $12 \%$ of the cases and malignant neoplasms were determined in $62 \%$ of the biopsy specimens ( $7 \%$ of all cases). In a prospective study, malignancy was reported in $2.7 \%$ of patients. ${ }^{12}$ In another study by Yaris et al. ${ }^{13}$ a biopsy was performed in $38.7 \%$ of the cases and malignant neoplasms were determined in $60 \%$ of biopsy specimens. In our study, the biopsy rate was lower than other studies because the children with cervical LAP were more frequently referred from the primary care to the pediatric oncology in fear of malignancy and as a result, the indication for biopsy was decided by a pediatric oncologist. However, the percentage of malignancy in biopsy specimens was similar to other studies reported by Pediatric Oncology- Departments. ${ }^{13,14}$

The studies demonstrated that lymphomas were the leading causes of cervical LAP in older children. ${ }^{6,13,14}$ Our results were compatible with previous studies as Hodgkin lymphoma was the leading cause of the malignant LAP group in our study. Similar results were reported by Celenk et al. ${ }^{15}$ who introduced Hodgkin lymphoma as the most common malignant diagnosis. On the other hand, non-Hodgkin lymphoma was reported to be the most common malignant cause of LAP in another study in which regions other than the cervical region were also included. ${ }^{16}$

The risk of malignancy in peripheral LAP increases with age. ${ }^{13}$ In our study, 30\% of patients in the 12-19 age group represented with malignant LAP. The size and duration of the LAP and local and systemic symptoms were suggested to predict malignancy and to help the decision of performing an excisional biopsy. ${ }^{12,16}$ Supraclavicular LAP has a particularly high prevalence of malignancy compared to other sites. ${ }^{4,13}$ Almost all patients (22/23) with supraclavicular localization had malignancy in our series and it is suggested that the supraclavicular LAP should be examined with a high suspicion of malignancy. Oguz and colleagues reported that the risk of malignancy in cervical LAP increases with the size of the lymph node, duration of the LAP, associated symptoms, and hepatosplenomegaly, which is compatible with our data. ${ }^{17}$ In our study, lesions smaller than one $\mathrm{cm}$ on palpation were always associated with a benign etiology, whereas half of the lesions bigger than three $\mathrm{cm}$ were due to malignancies. Besides, most of the LAP of $1-3 \mathrm{~cm}$ in size were in the benign group. In a manner consistent with other studies, ${ }^{12,14,17,18}$ our results showed that LAP larger than three $\mathrm{cm}$ in diameter had increased risk of malignancy. Based on these data, it is possible to say that the upper limit of LAP size can be three $\mathrm{cm}$ or more to be considered as a malignant process. Kumral et al. ${ }^{14}$ demonstrated the elevated risk for malignancy with symptoms that last more than 4 weeks. The duration of LAP reported in some studies was not associated with the presence of serious pathology. ${ }^{9,18}$ Besides, in a prospective study, the onset time of symptoms was similar between malignant and benign LAP groups. ${ }^{12}$ Malignancy was more common in the chronic LAP group in our study. However, this might be associated with delayed admission to healthcare as awareness of pediatric cancer is low in our population.

Unlike other studies, systemic symptoms like fever, night sweating, and weight loss were more frequent in malignant cases which can be explained by the predominance of Hodgkin lymphomas in our study. ${ }^{15,18}$ It has been shown that bilateral cervical LAP is an indicator of a reactive disease and malignancy is not associated with bilaterality. ${ }^{18,19}$ Similar to those, $61.5 \%$ of malignant LAP group was presented with unilateral LAP in our study. Besides, the frequency of unilateral LAP in the malignant LAP group was statistically higher than those in the benign LAP group and was associated with malignant disease $(\mathrm{p}=0.033)$.

Local features of cervical LAP may be predictive of malignancy. The lack of mobility seems to be highly associated with malignancy, which was also confirmed by Oguz et al. ${ }^{17} \mathrm{We}$ found that hard, fixed, and conglomerated LAP was associated with malignancy. Soldes 
et al. ${ }^{18}$ reported similar results with increased malignancy in hard, fixed lymph nodes. Conversely, the consistency of the LAP was reported as being unhelpful for differential diagnosis in another study. ${ }^{6}$ Therefore, localized or generalized LAP, and bilaterality or unilaterality may be misleading in determining whether the cause of cervical LAP is benign or malignant.

Previous studies showed that LAP in children regressed either spontaneously or with medication in most cases. ${ }^{12}$ And it is recommended that if the LAP does not regress in four weeks despite antibiotics, a biopsy should be performed. ${ }^{18}$ In our study, $67 \%$ of our patients' LAP regressed without further intervention. We consider that the enlargement or stable size of LAP in the follow-up can be a predictive factor for malignancy.

Simple hematological tests are usually required in children with cervical LAP. In our study, the risk of malignancy increased in the presence of anemia, leukocytosis, thrombocytosis, and elevated ESR. However, LDH and CRP levels were not associated with malignancy. Oguz et al. reported that anemia, leukocytosis, elevated ESR were associated with malignancy, which is compatible with our data. ${ }^{17}$ Reactive thrombocytosis due to malignancies and in particular those related to lymphomas have been well-defined. ${ }^{20}$ Conversely, children with thrombocytopenia were found to have a greater frequency of malignant LAP in some studies. ${ }^{12,17}$ The predominance of thrombocytosis in the malignant LAP group can be explained by the fact that most of the malignant cases were lymphoma in our study.

In conclusion, we found a low incidence of malignancy in cervical LAP in contrast to the other Pediatric Oncology-Hematology Departments. Children older than the age of 12 years, presented with LAP bigger than three $\mathrm{cm}$, a history of more than four weeks, and supraclavicular localization in combination with abnormal complete blood count and
LDH levels should alert the pediatrician for malignancy. But as studies are inconclusive on the predictive role of laterality, consistency, or conglomeration of lymph nodes, the differential diagnosis should not be used for decision making in cervical lymphadenopathy in children.

\section{Author contribution}

The authors confirm contribution to the paper as follows: study conception and design: Hilal Susam Şen, Süheyla Ocak; data collection: Hilal Susam Şen, Pınar Yılmazbaş; analysis and interpretation of results: Hilal Susam Şen; draft manuscript preparation: Hilal Susam Şen, Pınar Yilmazbaş, Süheyla Ocak.

All authors reviewed the results and approved the final version of the manuscript.

\section{Ethical approval}

This study was approved by the Noninterventional Clinical Research Ethics Board of Health Science University Okmeydani Training and Research Hospital (2019/1304).

\section{Source of funding}

No funding or other financial support for each author.

\section{Conflict of interest}

None declared.

\section{REFERENCES}

1. Meier JD, Grimmer JF. Evaluation and management of neck masses in children. Am Fam Physician 2014; 89: 353-358

2. Rajasekaran K, Krakovitz P. Enlarged neck lymph nodes in children. Pediatr Clin North Am 2013; 60: 923-936.

3. Park YW. Evaluation of neck masses in children. Am Fam Physician 1995; 51: 1904-1912. 
4. Locke R, Comfort R, Kubba $\mathrm{H}$. When does an enlarged cervical lymph node in a child need excision? A systematic review. Int J Pediatr Otorhinolaryngol 2014; 78: 393-401

5. Leung AKC, Robson WLM. Childhood cervical lymphadenopathy. J Pediatr Health Care 2004; 18: 3-7

6. Moore SW, Schneider JW, Schaaf HS. Diagnostic aspects of cervical lymphadenopathy in children in the developing world: a study of 1,877 surgical specimens. Pediatr Surg Int 2003; 19: 240-244

7. Papadopouli E, Michailidi E, Papadopoulou E, Paspalaki P, Vlahakis I, Kalmanti M. Cervical lymphadenopathy in childhood epidemiology and management. Pediatr Hematol Oncol 2009; 26: 454460.

8. Connolly A, MacKenzie K. Paediatric neck masses - a diagnostic dilemma. J Laryngol Otol 1997; 111: 541-545.

9. Wang J, Pie W, Yan J, et al. Unexplained cervical lymphadenopathy in children: predictive factors for malignancy. J Pediatr Surg 2010; 45: 784-788.

10. Citak EC, Koku N, Demirci M, Tanyeri B, Deniz $\mathrm{H}$. A retrospective chart review of evaluation of the cervical lymphadenopathies in children. Auris Nasus Larynx 2011; 38: 618-621.

11. Niedzielska G, Kotowski M, Niedzielski A, Dybiec E, Wieczorek P. Cervical lymphadenopathy in children--incidence and diagnostic management. Int J Pediatr Otorhinolaryngol 2007; 71: 51-56.

12. Bozlak S, Varkal MA, Yildiz I et al. Cervical lymphadenopathies in children: a prospective clinical cohort study. Int J Pediatr Otorhinolaryngol 2016; 82: 81-87.
13. Yaris N, Cakir M, Sözen E, Cobanoglu U. Analysis of children with peripheral lymphadenopathy. Clin Pediatr (Phila) 2006; 45: 544-549.

14. Kumral A, Olgun N, Uysal KM, Corapcioglu F, Oren H, Sarialioglu F. Assessment of peripheral lymphadenopathies: experience at a pediatric hematology-oncology department in Turkey. Pediatr Hematol Oncol 2002; 19: 211-218.

15. Celenk F, Baysal E, Aytac I, et al. Incidence and predictors of malignancy in children with persistent cervical lymphadenopathy. Int J Pediatr Otorhinolaryngol 2013; 77: 2004-2007.

16. Deosthali A, Donches K, DelVecchio M, Aronoff S Etiologies of pediatric cervical lymphadenopathy: a systematic review of 2687 subjects. Glob Pediatr Health 2019; 6: 1-7.

17. Oguz A, Karadeniz C, Temel AE, Citak EC, Okur V. Evaluation of peripheral lymphadenopathy in children. Pediatr Hematol Oncol 2006; 23: 549-561.

18. Soldes OS, Younger JG, Hirschl RB. Predictors of malignancy in childhood peripheral lymphadenopathy. J Pediatr Surg 1999; 34: 14471452.

19. Srouji IA, Okpala N, Nilssen E, Birch S, Monnery P. Diagnostic cervical lymphadenectomy in children: a case for multidisciplinary assessment and formal management guidelines. Int J Pediatr Otorhinolaryngol 2004; 68: 551-556.

20. Randi ML, Rossi C, Barbone E, Pietrogrande $\mathrm{F}$, Girolami A. Incidence of thrombocytosis in lymphomas. Leuk Lymphoma 1992; 7: 139-141. 